\title{
Optimization of initial dough moisture content for shepu enriched proso millet based multi grain pasta
}

\author{
P. V. Alfiya*, V. Palanimuthu', Santhi Mary Mathew and Sudha DeVi²
}

Department of Post Harvest Technology and Agricultural Processing, Kelappaji College of Agricultural Engineering and Technology, Tavanur, MALAPPURAM (KERALA) INDIA

${ }^{1}$ Department of Agricultural Engineering, University of Agricultural Sciences (G.K.V.K.), BENGALURU (KARANTAKA) INDIA ${ }^{2}$ Indian Institute of Crop Processing Technology, THANJAVUR (T.N.) INDIA

\begin{abstract}
SUMmARY :
Minor millets are rich in dietary fibre and other nutritional components. But their inclusion in daily urban diet is restricted due to lack of processing technology and value added products. Under this context, a study was undertaken to develop ready-to-cook pasta products using different small millets with proso millet as base by cold extrusion technique and La Montferrina Pasta Machine was employed. Among 16 proso millet based multi grain pasta formulations tested, four formulations namely, Proso:Wheat:Barnyard (30\%:60\%:10\%); Proso:Wheat:Foxtail (30\%:60\%:10\%); Proso:Wheat:Kodo (50\%:40\%:10\%); and Proso:Wheat:Little (50\%:40\%:10\%) were selected as best based on sensory evaluation of extruded pasta products. Enrichment study of above four pasta formulations with iron rich shepu powder (14.74 mg Fe/100 g) was carried out and depending upon the millets combination, an incorporation level of 1.0-1.5 per cent shepu powder was found to be optimum. The cooking characteristics namely, cooking time, swelling power and solid loss of shepu enriched multi grain pasta varied from to 7.15 to $7.45 \mathrm{~min}, 1.89$ to $2.20(\mathrm{~g} / \mathrm{g})$ and 4.80 to 8.65 per cent, respectively. For the production of proso millet based multi-grain pasta, optimum initial moisture content of dough was found to be 30 per cent. The developed pasta could be stored for over 3 months at ambient conditions without much quality deterioration (in terms of biochemical parameters, tristimulus colour, texture and microbial counts) and among the packages tested, LDPE film (200 gauge) was better compared to polypropylene film for pasta products. The Cost:Benefit Ratios $(>1: 1.74)$ worked out for proso millet based multi grain pasta products were highly favourable and, therefore, can be recommended for commercial exploitation.
\end{abstract}

KEY WoRDS : Minor millets, Pasta, Moisture content, Proso millet, Foxtail millet, Barnyard millet, Kodo millet, Shepu, Wheat, Little millet, Sensory score, Cold extrusion

How to cite this paper : Alfiya, P.V., Palanimuthu, V., Mathew, Santhi Mary and Devi, Sudha (2014). Optimization of initial dough moisture content for shepu enriched proso millet based multi grain pasta. Internat. J. Proc. \& Post Harvest Technol., 5 (2) : 105-113. 